Jurnal Akuntansi

Vol. 9, No.3 2019
DOI : https://doi.org/10.33369/j.akuntansi.9.3.173-186

Hal. $173-186$

\title{
PENGARUH CORPORATE SOCIAL RESPONSBILITY TERHADAP FINANCIAL DISTRESS DIMODERASI OLEH SIKLUS HIDUP PERUSAHAAN PADA TAHAP MATURE
}

\section{The Influence Of Corporate Social Responsbility On Financial Distress Moderated By Firm Life Cycle At Mature Stage}

\author{
Retno Wati Purwaningsih ${ }^{1)}$ dan Nurna Aziza ${ }^{2)}$ \\ Fakultas Ekonomi dan Bisnis Universitas Bengkulu ${ }^{1,2}$
}

\begin{abstract}
This research investigated to prove that corporate social responsbility has a negative effect on financial distress, and firm life cycle at mature stage strengthen effect of corporate social responsbility on financial distress. The populations of this study were all manufacturing companies listed on the Indonesia Stock Exchange during the years 2014-2017. Methods of data collection used purposive sampling techniques. There were 49 companies with 170 observations which fulfilled the criteria to be the study sample. This study uses a quantitative approach. Data was analyzed using logistic regression and moderated regression analysis (MRA) with help SPSS software.

The result showed that corporate social responsbility has a negative effect on financial distress, firm life cycle at mature stage strengthens the effect of corporate social responsbility on financial distress.

Keywords: Corporate social responsbility, Financial distress, Firm life cycle at mature stage
\end{abstract}

\begin{abstract}
ABSTRAK
Penelitian ini ditujukan untuk membuktikan bahwa tanggung jawab sosial perusahaan memiliki pengaruh negatif terhadap kesulitan keuangan, dan siklus hidup perusahaan pada tahap matang memperkuat pengaruh dari tanggung jawab sosial perusahaan pada kesulitan keuangan. Populasi penelitian ini adalah semua perusahaan manufaktur yang terdaftar di Bursa Efek Indonesia selama tahun 2014-2017. Metode pengumpulan data menggunakan teknik purposive sampling. Ada 49 perusahaan dengan 170 pengamatan yang memenuhi kriteria untuk menjadi sampel penelitian. Penelitian ini menggunakan pendekatan kuantitatif. Data dianalisis menggunakan regresi logistik dan moderated regression analysis (MRA) dengan bantuan software SPSS. Hasil penelitian menggambarkan bahwa terdapat hubungan negatif antara tanggung jawab sosial dan financial distress, siklus hidup perusahaan pada tahap matang memperkuat pengaruh social responsibilitybility terhadap financial distress.
\end{abstract}

Kata kunci: Tanggung jawab sosial perusahaan, Kesulitan keuangan, Siklus hidup perusahaan pada tahap matang

Corresponding author: retnowati070497@gmail.com

Email addresses for author: retnowati070497@gmail.com ${ }^{1)}$ izabkl.76@gmail.com ${ }^{2}$

First submission received: 13 Maret 2019

Revised submission received: 08 Oktober 2019

Accepted: 22 Oktober 2019 


\section{PENDAHULUAN}

Keberadaan perusahaan tidak dapat lepas dari publik yang ada di lingkungannya. Pihak manajemen tidak hanya terfokus dalam mengejar keuntungan semata saja, tetapi juga harus memperhatikan aspek lain seperti tanggung jawab sosial (people) dan tanggung jawab lingkungan (planet). Oleh karena itu ada tuntutan moral bagi pihak manajemen untuk memperhatikan kepentingan publik. Disinilah pentingnya manajemen melaksanakan corporate social responsibility. Corporate social responsbility merupakan kewajiban perusahaan untuk mempertanggungjawabkan dampak dari kegiatan operasinya, serta terus berusaha agar dampak tersebut bermanfaat bagi lingkungan di sekitar perusahaan dan masyarakat (Achda,2007). Pelaksanaan corporate social responsibility memberikan manfaat yang banyak bagi perusahaan yaitu berupa pengurangan biaya, meningkatkan produktivitas karyawan, dan lain sebagainya.Selain itu, corporate social responsibility dapat menjadi strategi perusahaan untuk meningkatkan image dan reputasi perusahaan. Reputasi perusahaan yang baik dapat meningkatkan kepercayaan masyarakat, sehingga dapat menarik minat masyarakat untuk membeli produk perusahaan maka tingkat penjualan dan profit perusahaan akan meningkat. Pelaksanaan corporate social responsbility juga memenuhi kebutuhan stakeholder yaitu berupa informasi, sehingga dengan terpenuhi kebutuhan stakeholder maka stakeholder akan memberikan dukungan baik dalam modal maupun kredit, sehingga kinerja keuangan perusahaan semakin meningkat.

Dengan semakin meningkatnya kinerja keuangan perusahaan tersebut, maka kemungkinan terjadinya financial distress pada suatu perusahaan juga semakin kecil. Menurut Fahmi (2013), financial distress merupakan keadaan dimana keuangan perusahaan mengalami penurunan yang dapat berakibat pada kebangkrutan perusahaan. Financial distress terjadi disebabkan oleh faktor internal, misalnya kerugian pada kegiatan operasi yang perusahaan pada beberapa tahun dan eksternal perusahaan seperti kebijakan pemerintah yang dapat menambah beban usaha, sehingga financial distress harus segera dimitigasi mengingat tidak sedikit fenomena-fenomena kebangkrutan yang terjadi oleh perusahaan-perusahaan di Indonesia.

Fenomena yang terjadi di Indonesia berkaitan dengan financial distress yaitu delisting beberapa perusahaan pada tahun 2015. Delisting terjadi jika saham mengalami penurunan atau tidak memenuhi kriteria persyaratan pencatatan, sehingga saham tersebut akan dikeluarkan dari pencatatan pada Bursa. Tahun 2015 BEI mengeluarkan 3 perusahaan yakni: PT. Davomas Abadi, Tbk, PT. Bank Ekonomi Raharja, Tbk, dan PT. Unitex, Tbk. DAVO mengalami delisting paksa oleh Bursa karena keberlanjutan usahanya mengkhawatirkan. Davo listing tahun 1994 dan dikeluarkan oleh Bursa pada bulan Januari 2015, sedangkan UNTX mengalami delisting pada bulan Desember 2015 disebabkan oleh kerugian operasional selama beberapa tahun terakhir. Maka dari itu, dapat disimpulkan terjadinya delisting pada perusahaanperusahaan publik di Bursa diakibatkan oleh kesulitan keuangan (financial distress).

Berdasarkan fenomena financial distress pada perusahaan-perusahaan yang terjadi di Indonesia, maka dari itu topik ini penting untuk diteliti agar dapat mengetahui apakah dengan pelaksanaan corporate social responsbility dapat memitigasi terjadinya financial distress pada perusahaan-perusahaan yang ada di Indonesia sehingga tidak terdapat lagi perusahaan yang mengalami financial distress yang mengakibatkan kebangkrutan. Namun, terdapat faktor lainnya yang mempengaruhi suatu perusahaan untuk melakukan corporate social responsbility yakni siklus hidup perusahaan. Siklus hidup perusahaan adalah proses perkembangan perusahaan melalui beberapa tahap linear dan berurutan (Bhaird, 2010). Berdasarkan konsep siklus hidup, siklus hidup perusahaan memiliki 4 tahap yakni start-up, growth, mature, decline. Pada tahap start-up, tingkat kenaikan keuntungan dan penjualan masih lamban karena perusahaan masih pada tahap memperkenalkan produk-produk yang dijualnya dan net income pada tahap ini masih cenderung bernilai negatif. Tahap yang kedua yaitu growth, dimana 
perusahaan mengalami pertumbuhan tingkat penjualan dan net income yang diperoleh lebih besar. Tahap selanjutnya yaitu mature, dimana tingkat penjualan berada pada tingkat puncak dan tingkat likuiditas tinggi. Tahap yang terakhir yaitu decline, dimana profitabilitas dan net income perusahaan mengalami penurunan. Pada tahap mature inilah yang dapat memperkuat hubungan antara corporate social responsbility dan financial distress, karena pada tahap ini perusahaan-perusahaan dapat meningkatkan pengimplementasian corporate social responsibility, hal ini dikarenakan selama tahap mature, perusahaan memiliki keunggulan dalam bersaing dan sumber daya yang lebih besar dari tahap lainnya. Pelaksanaan corporate social responsibility yang semakin meningkat tersebut nantinya bisa meminimalisir perusahaan dari risiko financial distress.

Berdasarkan pada pemikiran di atas, perlu dan penting untuk dilakukan penelitian agar dapat memberikan bukti empiris terhadap fenomena yang ada. Permasalahannya dan tujuannya adalah untuk menentukan apakah corporate social responsibility berpengaruh negatif terhadap financial distress, dan apakah siklus hidup perusahaan pada tahap mature memperkuat pengaruh negatif corporate social responsbility terhadap financial distress. Penelitian ini mereplikasi penelitian Hadi et al. (2017). Perbedaan penelitian ini dengan penelitian yang dilakukan oleh Hadi et al (2017) terletak pada sampel penelitian diambil, yang mana penelitian yang dilakukan oleh Hadi et al (2017) dari beberapa perusahaan publik yang ada di Australia, sedangkan penelitian ini menggunakan sampel yang diambil dari seluruh sektor industri manufaktur yang terdaftar di Bursa Efek Indonesia pada tahun 2014-2017. Penelitian ini menggunakan sektor manufaktur disebabkan karena perusahaan-perusahaan manufaktur lebih banyak mempunyai pengaruh/dampak sosial dan lingkungan di sekitarnya sebagai akibat dari aktivitas yang dilakukan perusahaan dan lebih rentan mengalami financial distress karena kegiatan utama industri manufaktur adalah mengolah sumber daya menjadi barang jadi melalui suatu proses pabrikasi yang membutuhkan bahan baku dan industri akan melakukan pembelian bahan baku baik dengan pinjaman atau kredit. Jika keadaan makro ekonomi tidak mendukung, misalnya tingginya bunga atas pinjaman, maka perusahaan kemungkinan mengalami financial distress.

\section{KERANGKA TEORITIS DAN HIPOTESIS}

\section{Teori Legitimasi (Legitimacy Theory)}

Brown dan Deegan (1998), teori legitimasi menyatakan bahwa perusahaan terus berusaha meyakinkan dan memastikan bahwa perilaku dari perusahaan yang beroperasi sesuai dengan norma masyarakat. Menurut teori legitimasi, perusahaan harus meyakinkan aktivitas yang dilakukannya serta kinerjanya bisa diterima masyarakat, sehingga semakin lama keberlangsungan perusahaan maka informasi sosial yang diungkapkan perusahaan tersebut juga semakin banyak (Utami dan Prastiti, 2011). Salah satu perwujudan teori legitimasi yaitu pengungkapan corporate social responsibility.

Pengungkapan corporate social responsbility guna mempertanggungjawabkan akibat dari aktivitas operasinya. Corporate social responsibility dilakukan agar mendapatkan penilaian positif serta legitimasi dari masyarakat (Subiantoro dan Mildawati, 2015), serta untuk menaikkan image atau reputasi perusahaan (Gray et al., 1988), sehingga dapat memaksimalkan kinerja keuangan perusahaan tersebut (Kiroyan, 2006).

\section{Teori Sinyal (Signalling Theory)}

Wolk et al. (2001), Teori sinyal menjelaskan bahwa perusahaan memberikan informasi mengenai laporan keuangan kepada pihak eksternal dikarenakan terdapat asimetri informasi antara perusahaan dengan pihak eksternal, yang dapat diatasi dengan mengurangi asimetri 
informasi tersebut yaitu dengan cara memberikan sinyal pada pihak eksternal dalam bentuk informasi mengenai kegiatan perusahaan, misalnya mengenai aktivitas corporate social responsbility yang dimuat dalam laporan tahunan.

Informasi ini dijadikan sebagai sarana untuk memberikan tanda atau sinyal kepada stakeholders tentang kepedulian perusahaan terhadap lingkungan disekitarnya, dan tidak sekedar menyediakan informasi karena berdasarkan ketentuan peraturan tetapi juga menyediakan informasi yang lebih bagi para stakeholders. Tanda-tanda atau sinyal ini diharapkan dapat diterima secara positif oleh pasar sehingga mampu mempengaruhi kinerja pasar perusahaan yang tercermin dalam harga pasar saham perusahaan.

Pengungkapan corporate social responsibility juga merupakan sinyal positif yang terkait dengan kualitas manajemen dan juga sinyal kepada investor dan stakeholder lainnya di mana perusahaan secara aktif ikut serta dalam praktik-praktik sosial yang akan direspon nantinya oleh stakeholder dan investor melalui perubahan harga saham dan laba perusahaan (Kurnianto,2011). Selain itu, kinerja sosial perusahaan yang baik membantu perusahaan untuk mendapatkan keandalan reputasi dari pasar modal dan utang, dimana hal ini akan menarik investor untuk berinvestasi, sehingga perusahaan dapat menghindari kemungkinan terjadinya financial distress.

\section{Financial Distress}

Fahmi (2013) mendefinisikan bahwa financial distress adalah kondisi dimana keuangan perusahaan mengalami penurunan sebelum terjadinya kebangkrutan atau likuidasi. Model Altman Z-Score dapat digunakan oleh perusahaan untuk memprediksi tingkat financial distress, sehingga perusahaan dapat melakukan tindakan pencegahan jika terindikasi berada pada kondisi financial distress. Model Altman ini mengkombinasikan beberapa rasio untuk menghasilkan model prediksi yang dapat digunakan oelh semua perusahaan. Adapun rasiorasio keuangan tersebut yaitu working capital/total assets, retained earnings/total assets, EBIT/ total assets, market value of equity/book value of total liabilities, sales/total assets (Darsono dan ashari (2005:105).

\section{Corporate Social Responsbility (CSR)}

Menurut The World Business Council on Sustainable Development (WBCSD) menyatakan corporate social responsbility adalah komitmen dari suatu perusahaan untuk memberikan kontribusi terhadap pembangunan ekonomi yang berkelanjutan dan melaksanakan etika keperilakuan. Achda (2007) mengartikan kewajiban perusahaan untuk mempertanggungjawabkan dampak dari kegiatan operasinya, serta terus berusaha agar dampak tersebut bermanfaat bagi lingkungan disekitar perusahaan dan masyarakat. Corporate Social Responsibility berasal dari konsep triple bottom line oleh Elkington yang menjelaskan bahwa perusahaan untuk dapat tumbuh berkelanjutan, tidak hanya memperhatikan aspek profit atau keuntungan saja, tetapi juga harus memperhatikan aspek lain seperti people berarti tanggung jawab dengan sosial, dan planet berarti tanggung jawab terhadap lingkungan(Noviana, 2010).

\section{Konsep Siklus Hidup}

Siklus hidup perusahaan adalah proses perkembangan perusahaan melalui beberapa tahap yang linear dan berurutan (Bhaird, 2010 dalam Vidiastuty, 2012) yang memiliki 4 tahap yaitu introduction/start-up, growth (pertumbuhan), mature (matang), dan decline (penurunan). Menurut Juniarti dan Limanjaya (2005), tahap-tahap siklus hidup perusahaan memiliki kharakteristik yaitu sebagai berikut: pertama, tahap start-up, perusahaan mengalami pertumbuhan penjualan, keuntungan yang lamban dan net income masih cenderung bernilai negatif. Tahap growth, dimana perusahaan mengalami pertumbuhan tingkat penjualan dan net income yang diperoleh lebih besar. Tahap mature, dimana tingkat penjualan perusahaan 
mengalami peningkatan yang besar dan tingkat likuiditas tinggi. Tahap decline, dimana profitabilitas dan net income perusahaan mengalami penurunan.

\section{Ukuran Perusahaan (Size)}

Ukuran perusahaan (size) ialah nilai yang menggambarkan besar atau kecilnya suatu perusahaan (Butar dan Sudarsi, 2012). Ukuran perusahaan menggambarkan besarnya total aset yang dimiliki oleh perusahaan. Semakin besar total aset perusahaan maka kondisi financial perusahaan akan lebih stabil dan kuat dalam kondisi financial distress.

\section{Leverage}

Menurut Fahmi (2013), leverage digunakan untuk mengukur seberapa besar suatu perusahaan dibiayai dengan utang. Jika perusahaan terlalu banyak didanai oleh utang maka perusahaan harus menangggung kewajiban dan bunga utang yang lebih besar dimasa mendatang. Jika terlalu besar dapat mengakibatkan suatu perusahaan mengalami financial distress.

\section{Cash Holding}

Menurut Gill dan Shah (2012), Cash holding yaitu kas yang dimiliki dan tersedia untuk berinvestasi pada aset fisik oleh perusahaan, serta untuk membagikan dividen. Perusahaan yang memiliki cash holding yang cukup, maka kemungkinan terjadinya financial distress semakin rendah, karena kas yang tersedia cukup untuk melunasi kewajiban baik jangka pendek ataupun jangka panjang.

\section{Pengembangan Hipotesis}

\section{Corporate Social Responsbility dan Financial Distress}

Menurut teori legitimasi, suatu perusahaan akan terus berusaha untuk meyakinkan bahwa perilaku dari perusahaan telah sesuai dengan norma pada masyarakat. Perusahaan yang melaksanakan corporate social responsbility dapat meningkatkan legitimasi masyarakat, sehingga masyarakat akan membeli produk atau jasa dari perusahaan tersebut, maka laba akan semakin meningkat dan juga memenuhi kebutuhan stakeholder berupa informasi sehingga stakeholder akan memberikan dukungan dalam bentuk modal maupun kredit, sehingga kinerja keuangan perusahaan semakin baik maka semakin rendah kemungkinan terjadinya financial distress. Hal ini juga sesuai dengan teori sinyal bahwa dengan melaksanakan corporate social responsbility, perusahaan dapat memberikan tanda atau sinyal positif kepada investor, dikarenakan para investor lebih senang membeli saham dari perusahaan yang melakukan corporate social responsbility (Baron, 2007), sehingga dengan modal yang ditanam oleh para investor, maka perusahaan dapat menghindari kemungkinan terjadinya financial distress.

$\mathrm{H}_{1}$ : Corporate social responsbility berpengaruh negatif terhadap financial Distress.

\section{Siklus Hidup Perusahaan, Corporate Social Responsbility, Financial Distress}

Perusahaan pada tahap mature dalam kondisi siap investasi, kemudian dikombinasikan dengan legitimasi yang efektif dengan masyarakat melalui pelaksanaan kegiatan corporate social responsibility, dimana hal ini sesuai dengan teori legitimasi sehingga perusahaan yang melaksanakan corporate social responsbility diharapkan dapat memitigasi financial distress. Selain itu, perusahaan pada tahap mature (dewasa) memanfaatkan hubungan dengan para stakeholder-nya. Pada tahap mature (matang) inilah, hubungan antara corporate social responsibility dan financial distress diperkuat, karena pada tahap ini perusahaan dapat meningkatkan pelaksanaan corporate social responsbility dikarenakan perusahaan sudah mempunyai keunggulan kompetitif berupa sumber daya yang besar, sehingga dengan semakin 
meningkatnya pelaksanaan corporate social responsbility maka kemungkinan terjadinya financial distress juga lebih rendah. Maka, hipotesis yang dapat dirumuskan sebagai berikut : $\mathrm{H}_{2}$ : Siklus hidup perusahaan pada tahap mature memperkuat pengaruh corporate social responsbility terhadap financial distress.

\section{METODE PENELITIAN}

\section{Jenis Penelitian}

Berdasarkan jenis data yang diteliti, penelitian ini termasuk ke dalam jenis penelitian empiris (empirical research) dan bersifat kuantitatif yang menggambarkan dan menjelaskan pengaruh fenomena yang dijadikan objek penelitian.

\section{Variabel Dependen}

Variabel dependen pada penelitian ini yakni financial distress. Financial Distress diukur dengan menggunakan model Altman Z-score yang mewakili rasio-rasio tertentu, yakni:

$$
Z=1,2 X_{1}+1,4 X_{2}+3,3 X_{3}+0,6 X_{4}+0,99 X_{5}
$$

Keterangan:

$Z=$ Financial Distress

$X_{1}=$ Working Capital/Total Assets

$X_{2}=$ Retained Earnings/Total Assets

$X_{3}=$ EBIT/Total Assets

$X_{4}=M V$ of Equity/BV of Total Liabilities

$X_{5}=$ Sales/Total Assets

Perusahaan dengan nilai Z score $>$ 2,99 dikategorikan mengalami financial distress dan diberi nilai 0 , begitupun sebaliknya jika nilai Z-Score $<2,99$ dikategorikan mengalami financial distress dan diberi nilai 1.

\section{Variabel Independen}

Variabel independen pada penelitian ini adalah corporate social responsbility. Pengungkapan corporate social responsbility diukur dengan berpedoman pada GRI G4 dengan 75 Indikator seperti yang dikembangkan oleh Cho et al. (2013) yang diklasifikasikan dalam CSR positif dan negatif. Item CSR positif dan negatif diukur dengan logaritma natural dari jumlah item CSR positif atau negatif dengan 1 tahun sebelum tahun pengamatan ( $t-1)$.

$$
\begin{aligned}
& \text { POS_CSR }_{\mathrm{t}-1}=(\mathrm{Ln}) \text { CSR Positif } \\
& \text { NEG_CSR }_{\mathrm{t}-1}=(\mathrm{Ln}) \text { CSR Negatif } \\
& \text { TOTAL CSR } \mathrm{t}-1=\text { Jumlah (Ln) CSR Positif dan Negatif }
\end{aligned}
$$

\section{Variabel Moderasi}

Variabel moderating pada penelitian ini adalah siklus hidup perusahaan pada tahap mature. Siklus hidup perusahaan diproksikan dengan retained earnings terhadap total equity (RE/TE). Lalu, dihitung nilai median dari rasio RE/TE yang berada di atas nilai median dikategorikan dalam tahap mature, sedangkan di bawah nilai median dikategorikan dalam tahap start up, dimana pada tahap mature saja yang akan menjadi sampel.

$$
\text { LC = Retained Earning/Total Equity }
$$




\section{Variabel Kontrol}

Ukuran perusahaan diukur dengan menggunakan logaritma natural dari total aset.

$$
\text { Size }=(\text { Ln }) \text { of Total Assets }
$$

Leverage diukur dengan membagi total liabilitas dengan total aset.

$$
\text { Leverage }=\frac{\text { Total Liabilities }}{\text { Total Aset }}
$$

Cash holding diukur dengan membagi jumlah kas dan short investment perusahaan dengan total aset yang dihitung dengan rumus sebagai berikut:

$$
\text { Cash Holding }=\frac{\text { Cash }+ \text { Short Term Investment }}{\text { Total Assets }}
$$

\section{Populasi dan Sampel Penelitian}

Penelitian ini menggunakan objek penelitian perusahaan manufaktur yang listed di Bursa Efek Indonesia (BEI) periode 2014-2017. Pengambilan sampel penelitian menggunakan metode purposive sampling, dengan kriteria perusahaan sebagai berikut :

1. Perusahaan konsisten menerbitkan laporan keuangan (auditan) dan laporan tahunan tahun 2014 - 2017 pelaporan keuangan berakhir 31 Desember.

2. Perusahaan yang mengungkapkan CSR selama tahun $2014-2017$.

3. Menyajikan laporan keuangan menggunakan mata uang Rupiah.

4. Memiliki data lengkap yang terkait dengan variabel-varibel yang digunakan.

5. Perusahaan manufaktur pada tahap mature dalam siklus hidup perusahaan.

\section{Metode Analisis Data}

Metode analisis yang dipakai dalam penelitian ini yaitu statistik deskriptif, asumsi klasik yaitu uji normalitas, uji kelayakan model (Overall Fit Model), matriks klasifikasi 2x2, koefisien determinasi, analisis regresi logistik dan uji hipotesis dengan bantuan aplikasi SPSS 23.0.

\section{Analisis Regresi Logistik}

Metode statistik yang digunakan untuk menguji hipotesis adalah analisis regresi logistik. Model persamaan regresi logistik yang akan diteliti dalam pengujian hipotesis adalah sebagai berikut :

Model regresi (1)

$$
\mathrm{FD}_{\mathrm{it}}=\alpha+\beta_{1} \mathrm{CSR}_{\mathrm{it}}+\beta_{2} \mathrm{SIZE}_{\mathrm{it}}+\beta_{3} \mathrm{LEV}_{\mathrm{it}}+\beta_{4} \mathrm{CH}_{\mathrm{it}}+\varepsilon \text { it }
$$

Uji interaksi atau Moderated Regression Analysis (MRA) dilakukan untuk menguji hipotesis 2. Model persamaannya adalah:

Model regresi (2)

$$
\mathrm{FD}_{\mathrm{it}}=\alpha+\beta_{1} \mathrm{CSR}_{\mathrm{it}}+\beta_{2} \text { MATURE }_{\mathrm{it}}+\beta_{3} \text { CSR.MATURE }_{\mathrm{it}}+\beta_{4} \mathrm{SIZE}_{\mathrm{it}}+\beta_{5} \mathrm{LEV}_{\mathrm{it}}+\beta_{6} \mathrm{CH} \text { it }+\varepsilon_{\text {it }}
$$

Keterangan :

FDit

$\alpha \quad=$ Konstanta

CSR = Corporate Social Responsbility

= Financial Distress, variabel kategorikal yang tidak mengalami financial distress diberi kode 1, dan kode 0 untuk yang mengalami financial distress 
PENGARUH CORPORATE SOCIAL RESPONSBILITY TERHADAP FINANCIAL DISTRESS DIMODERASI OLEH SIKLUS HIDUP PERUSAHAAN PADA TAHAP MATURE

Retno Wati Purwaningsih dan Nurna Aziza

$\beta_{1-} \beta_{6} \quad=$ Koefisien Regresi

SIZE $\quad$ it Ukuran Perusahaan perusahaan

$\mathrm{LEV}_{\text {it }} \quad=$ Leverage perusahaan

$\mathrm{CH}_{\text {it }} \quad=$ Cash Holding

CSR.MATURE $_{\mathrm{it}} \quad=$ Interaksi antara CSR dengan tahap mature

\section{HASIL DAN PEMBAHASAN}

\section{Populasi dan Sampel Penelitian}

Berdasarkan kriteria yang telah ditetapkan, maka jumlah sampel penelitian ini adalah 49 perusahaan dengan 170 observasi yang disajikan pada tabel 1 sebagai berikut :

Tabel 1. Sampel Penelitian

\begin{tabular}{lcccc}
\hline \multirow{2}{*}{ Kriteria Penetapan Sampel } & \multicolumn{4}{c}{ Jumlah Perusahaan } \\
\cline { 2 - 6 } & $\begin{array}{c}\text { Tahun } \\
2014\end{array}$ & $\begin{array}{c}\text { Tahun } \\
2015\end{array}$ & $\begin{array}{c}\text { Tahun } \\
2016\end{array}$ & $\begin{array}{c}\text { Tahun } \\
2017\end{array}$ \\
\hline $\begin{array}{l}\text { Perusahaan manufaktur yang listed di BEI tahun 2014 } \\
2017\end{array}$ & 144 & 144 & 144 & 144 \\
\hline $\begin{array}{l}\text { Perusahaan yang laporan tahunan dan laporan keuangan } \\
\text { tidak dapat diakses melalui website BEI } \\
\text { (www.idx.co.id) }\end{array}$ & $(19)$ & $(19)$ & $(19)$ & $(19)$ \\
\hline Perusahaan yang tidak mengungkapkan CSR & $(2)$ & $(2)$ & $(2)$ & $(2)$ \\
\hline $\begin{array}{l}\text { Perusahaan yang menggunakan mata uang selain Rupiah } \\
\text { (US Dollar) }\end{array}$ & $(27)$ & $(27)$ & $(27)$ & $(27)$ \\
\hline Perusahaan yang tidak memiliki kelengkapan data & $(9)$ & $(9)$ & $(9)$ & $(9)$ \\
\hline $\begin{array}{l}\text { Perusahaan yang tidak berada pada siklus hidup } \\
\text { perusahaan tahap mature }\end{array}$ & $(45)$ & $(44)$ & $(44)$ & $(45)$ \\
\hline $\begin{array}{l}\text { Jumlah observasi yang memenuhi kriteria penelitian } \\
\text { Jumlah Observasi (Tahun 2014-2017) }\end{array}$ & & 42 & 43 & 42 \\
\hline
\end{tabular}

Statistik deskriptif dalam penelitian ini disajikan pada Tabel berikut :

Tabel 2. Statistik Deskriptif Variabel Penelitian

\begin{tabular}{lcrccc}
\hline \multicolumn{1}{c}{ Variabel } & $\mathrm{n}$ & Minimum & Maksimum & Mean & $\begin{array}{c}\text { Standar } \\
\text { Deviasi }\end{array}$ \\
\hline CSR & 170 & 1,6094 & 3,1781 & 2,4263 & 0,3769 \\
\hline MATURE & 170 & 0,4441 & 2,47 & 0,7826 & 0,2601 \\
\hline SIZE & 170 & 25,2156 & 33,3202 & 28,7473 & 1,7411 \\
\hline LEV & 170 & 0,061 & 3,0291 & 0,4148 & 0,3288 \\
\hline $\mathrm{CH} \quad 170$ & 0,0021 & 0,6325 & 0,1537 & 0,137 \\
\hline $\begin{array}{c}\text { Kategori Financial } \\
\text { Distress }\end{array}$ & Jumlah & Persentase & Minimum & Maksimum \\
\hline $\begin{array}{c}\text { Observasi perusahaan yang } \\
\text { mengalami financial } \\
\text { distress (Kategorikal 1) }\end{array}$ & 31 & $18 \%$ & $-1,1921$ & 2,9436 \\
\hline $\begin{array}{c}\text { Observasi perusahaan yang } \\
\text { tidak mengalami financial } \\
\text { distress (Kategorikal 0) }\end{array}$ & 139 & $82 \%$ & 3,077 & 22,9096 \\
\hline
\end{tabular}


Hasil uji normalitas dirangkum dalam tabel berikut ini :

Tabel 3. Uji Normalitas Data

\begin{tabular}{lccc}
\hline Variabel & $\begin{array}{c}\text { Kolmogrov } \\
\text { Smirnov }\end{array}$ & $\begin{array}{c}\text { Asymp. Sig. (2- } \\
\text { tailed) }\end{array}$ & Keterangan \\
\hline FD & 0,501 & 0,000 & Tidak Normal \\
\hline CSR & 0,140 & 0,000 & Tidak Normal \\
\hline MATURE & 0,177 & 0,000 & Tidak Normal \\
\hline SIZE & 0,084 & 0,005 & Tidak Normal \\
\hline LEV & 0,168 & 0,000 & Tidak Normal \\
\hline CH & 0,141 & 0,000 & Tidak Normal \\
\hline
\end{tabular}

Berdasarkan tabel di atas untuk pengujian normalitas data menunjukan bahwa variabelvariabel dalam penelitian ini secara keseluruhan dapat disimpulkan tidak terdistribusi secara normal karena nilai Asymp. Sig (2-tailed) lebih kecil dari 0,05.

\section{Uji Kelayakan Model (Overall Fit Model)}

Tabel 4. Uji Kelayakan Model

\begin{tabular}{|c|c|c|c|c|}
\hline \multicolumn{5}{|c|}{ Model regresi (1) } \\
\hline Model & $\begin{array}{c}-2 \log \\
\text { Likelihood }\end{array}$ & $\begin{array}{c}\text { Chi-square (Omnibus Test Coefficient } 4 \\
\text { Variables) }\end{array}$ & $\mathrm{df}$ & Sig. \\
\hline Intercept Only & 161,481 & & & \\
\hline Final & 85,338 & 76,142 & 4 & 0,000 \\
\hline \multirow{2}{*}{\multicolumn{2}{|c|}{ Koefisien Determinasi $\left(\mathrm{R}^{2}\right)$}} & \multicolumn{3}{|l|}{ Nagelkerke R Square } \\
\hline & & \multicolumn{3}{|l|}{0,589} \\
\hline \multicolumn{5}{|c|}{ Model regresi (2) } \\
\hline Model & $\begin{array}{c}-2 \log \\
\text { Likelihood }\end{array}$ & $\begin{array}{c}\text { Chi-square (Omnibus Test Coefficient } 6 \\
\text { Variables) }\end{array}$ & $\mathrm{df}$ & Sig. \\
\hline Intercept Only & 161,481 & & & \\
\hline Final & 59,718 & 101,762 & 6 & 0,000 \\
\hline \multirow{2}{*}{\multicolumn{2}{|c|}{ Koefisien Determinasi $\left(\mathrm{R}^{2}\right)$}} & \multicolumn{3}{|l|}{ Nagelkerke R Square } \\
\hline & & \multicolumn{3}{|l|}{0,735} \\
\hline
\end{tabular}

Berdasarkan Tabel 4 diatas, hasil regresi logistik pada model regresi (1) yaitu hasil - $2 L L$ intercept only dengan $2 L L$ final terjadi penurunan nilai dan penurunan nilainya memiliki nilai signifikan dibawah 5\% dengan nilai chi square 76,142 dan begitupun dengan model regresi (2), nilai $2 L L$ intercept only dengan $2 L L$ final terjadi penurunan nilai dan penurunan nilainya memiliki nilai signifikan dibawah 5\% dengan nilai chi square 101,762 maka dapat disimpulkan bahwa model regresi (2) adalah model yang signifikan (fit).

\section{Koefisien Determinasi}

Nilai nagelkerke's $R$ square pada model regresi (1) sebesar 0,589. Hal ini menggambarkan bahwa variabel independen mampu menjelaskan variabel financial distress sebesar 58,9\% dan sisanya diperjelas oleh variabel lainnya yang tidak dimasukkan kedalam regresi. Selanjutnya, nilai nagelkerke's $R$ square pada model regresi (2) sebesar 0,735 . Hal ini menggambarkan bahwa variabel independen mampu menjelaskan variabel financial distress sebesar 73,5\% dan sisanya diperjelas oleh variabel lainnya yang tidak dimasukkan kedalam regresi. 


\section{Uji Matriks Klasifikasi 2x2}

Tabel 5. Uji Matriks Klasifikasi 2x2

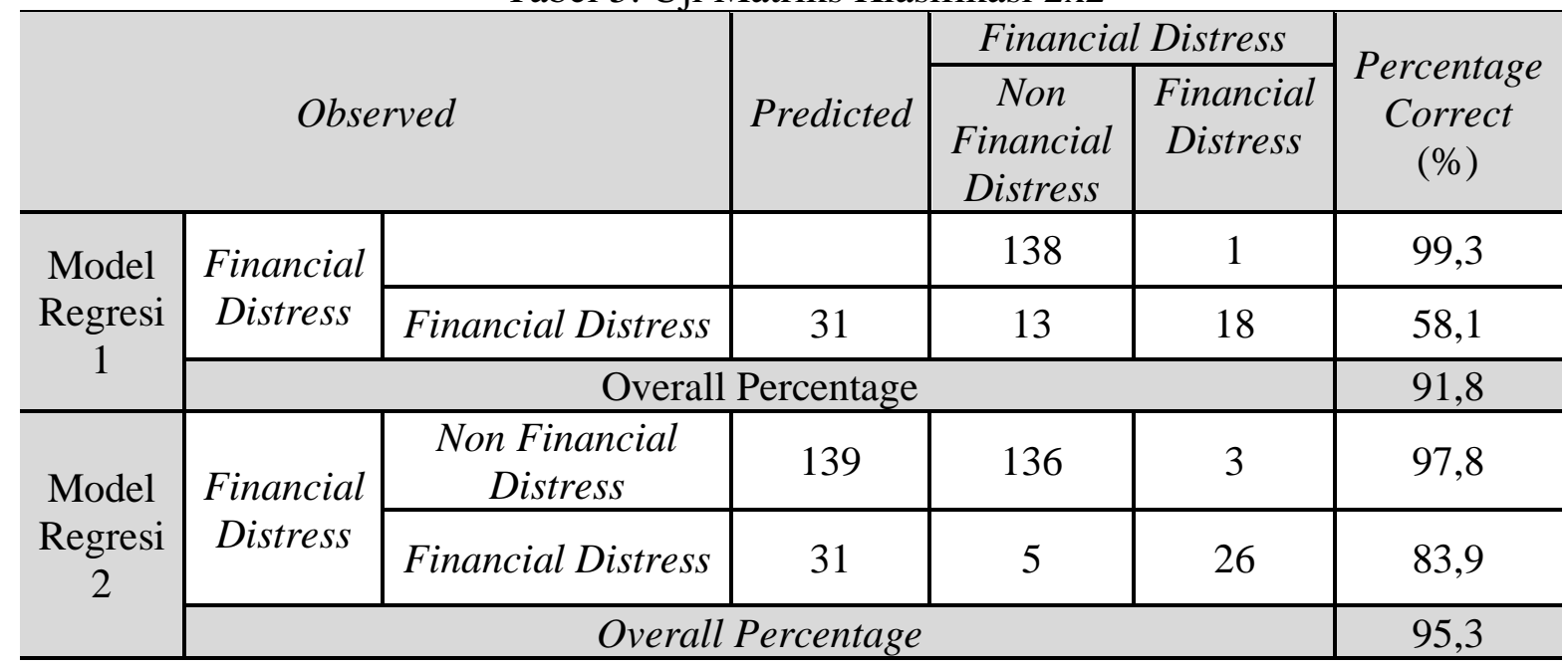

Tabel klasifikasi dalam penelitian ini menggambarkan bahwa kemampuan pengelompokkan atas variabel dependen hampir sempurna dan tepat yaitu dengan nilai overall percentage sebesar 91,8\% untuk model regresi 1 dan 95,3\% untuk model regresi 2.

\section{Pengujian Hipotesis}

Hasil uji analisis regresi linier logistik untuk masing-masing model disajikan pada tabel 6 sebagai berikut :

Tabel 6. Hasil Uji Analisis Regresi Logistik

\begin{tabular}{l|c|c|c|c}
\hline \multirow{2}{*}{ Variabel in the Equation } & \multicolumn{2}{|c|}{ Model 1 } & \multicolumn{2}{c}{ Model 2 } \\
\cline { 2 - 5 } & Koefisien $(\beta)$ & Sig. & Koefisien $(\beta)$ & Sig. \\
\hline CSR & $-4,278$ & 0,000 & 1,349 & 0,439 \\
\hline MATURE & & & 22,176 & 0,003 \\
\hline SIZE & 0,128 & 0,447 & 0,313 & 0,154 \\
\hline LEV & 5,282 & 0,004 & 8,616 & 0,000 \\
\hline CH & $-8,288$ & 0,054 & $-11,701$ & 0,059 \\
\hline CSR_MATURE & & & $-11,986$ & 0,000 \\
\hline
\end{tabular}

Pengujian untuk hipotesis pertama ingin membuktikan bahwa terdapat pengaruh negatif antara corporate social responsbility dan financial distress. Berdasarkan tabel 6 untuk model regresi (1), hasil pengujian dari regresi logistik untuk variabel CSR menunjukkan koefisien regresi yang negatif sebesar $-4,278$ dengan signifikansi 0,000 dibawah 5\%, sehingga dari hasil pengujian dapat disimpulkan bahwa terdapat pengaruh signifikan dan negatif antara CSR dan financial distress, sehingga disimpulkan bahwa hasil penelitian hipotesis pertama diterima.

Berdasarkan tabel 6 untuk model regresi (2), hasil pengujian dari regresi logistik untuk interaksi variabel CSR dan siklus hidup perusahaan pada tahap mature (MATURE) menunjukkan koefisien regresi yang negatif sebesar -11,986 dan nilai signifikasi 0,000 dibawah $5 \%(\mathrm{t}<5 \%)$, maka dapat disimpulkan hipotesis kedua diterima.

\section{Pembahasan}

\section{Pengaruh CSR Pada Financial Distress}

Dari hasil pengujian regresi logistik disimpulkan bahwa terdapat pengaruh negatif antara csr dan financial distress. Pelaksanaan corporate social responsbility dapat memitigasi 
financial distress yang dapat terjadi pada suatu perusahaan (Hadi et al., 2017), hal ini terjadi disebabkan oleh perusahaan tidak lagi memandang corporate social responsbility sebagai sumber biaya melainkan sebagai pusat laba di masa mendatang, sehingga dengan melaksanakan corporate social responsbility perusahaan akan memperoleh berbagai manfaat yaitu berupa pengurangan biaya, meningkatkan produktivitas karyawan, menghasilkan keuntungan dengan keragaman produk, meningkatkan penjualan, meningkatkan image atau reputasi perusahaan, serta menarik stakeholder dan shareholder untuk lebih mempercayakan menanamkan modal mereka kepada perusahaan, sehingga ini dapat meningkatkan profit dan kinerja keuangan perusahaan yang melaksanakan dan mengungkapkan corporate social responsbility sehingga pertanda terjadinya financial distress semakin rendah.

Penelitian ini mendukung teori legitimasi yang mengungkapkan bahwa perusahaan terus berusaha meyakinkan dan memastikan bahwa perilaku dari perusahaan yang beroperasi sesuai terhadap batasan serta norma masyarakat pada umumnya (Brown dan Deegan 1998). Pelaksanaan corporate social responsbility merupakan salah satu bukti bahwa perusahaan tidak terfokus pada keuntungan semata, tetapi juga perduli dengan lingkungan dan masyarakat dimana perusahaan berdiri. Selain itu, corporate social responsbility dapat meningkatkan image serta reputasi perusahaan, akibatnya hal ini dapat menarik minat masyarakat untuk membeli produk perusahaan sehingga tingkat penjualan dan profit akan meningkat. Selain itu, dengan mengungkapkan corporate social responsbility juga akan memenuhi kebutuhan stakeholder yaitu informas, sehingga stakeholder akan memberikan dukungan penuh kepada perusahaan dalam bentuk modal maupun kredit serta dukungan lainnya, sehingga kinerja keuangan perusahaan semakin meningkat dan pertanda terjadinya financial distress semakin rendah.

Kemudian, penelitian ini juga membuktikan teori sinyal (Signalling Theory). Teori sinyal menjelaskan bahwa perusahaan memberikan informasi mengenai laporan keuangan kepada pihak eksternal dikarenakan terdapat asimetri informasi antara perusahaan dengan pihak eksternal, yang dapat diatasi dengan mengurangi asimetri informasi tersebut yaitu dengan cara memberikan tanda atau sinyal pada pihak eksternal dalam bentuk informasi mengenai kegiatan perusahaan (Wolk et al., 2001). Pengungkapan corporate social responsbility yang luas memberikan tanda atau sinyal positif kepada investor maupun stakeholder perusahaan, serta informasi tentang perusahaan yang disampaikan kepada stakeholder dan investor juga semakin luas. Stakeholder dan investor akan lebih percaya untuk menanamkan modal mereka kepada perusahaan yang lebih aktif ikut serta dalam praktik-praktik sosial, sehingga perusahaan akan menggunakan modal tersebut untuk aktivitas perusahaan dalam rangka meningkatkan laba, dan menghindari kemungkinan terjadinya financial distress. Hasil penelitian ini selaras dengan penelitian Gross (2017), Hadi et al. (2017) dan Gavalas (2018) yang menunjukkan hasil bahwa perusahaan dengan pelaksanaan corporate social responsibility yang tinggi dapat mengurangi kemungkinan terjadinya financial distress.

\section{Siklus Hidup Perusahaan pada Tahap Mature Memperkuat Pengaruh Corporate Social Responsbility terhadap Financial Distress}

Dari hasil pengujian regresi logistik disimpulkan bahwa siklus hidup perusahaan pada tahap mature memperkuat pengaruh corporate social responsbility terhadap financial distress. Siklus hidup pada tahap mature membuat perusahaan lebih bisa meningkatkan pelaksanaan corporate social responsbility (Hasan dan Habib, 2017), dikarenakan tahap mature perusahaan sudah mempunyai keunggulan kompetitif dan sumber daya yang tinggi, sehingga perusahaan akan berinvestasi lebih banyak dalam kegiatan yang berhubungan dengan corporate social responsibility untuk mempertahankan reputasinya. Semakin perusahaan melaksanakan dan mengungkapkan corporate social responsbility maka semakin rendah kemungkinan terjadinya financial distress 
Penelitian ini mendukung teori legitimasi yang menunjukkan bahwa perusahaan terus berusaha meyakinkan dan memastikan bahwa perilaku dari perusahaan yang beroperasi sesuai dengan norma masyarakat (Brown dan Deegan 1998). Keberlangsungan hidup suatu perusahaan bergantung pada hubungannya dengan masyarakat sekitar serta lingkungan dimana perusahaan tersebut berdiri. Perusahaan ditahap mature ataupun tahap lainnya tetap akan melaporkan pengungkapan CSR untuk mendapatkan legitimasi, dikarenakan kegiatan CSR di Indonesia bersifat wajib berdasarkan yang diatur dalam, UU No. 40 tahun 2007 tentang Perseroan Terbatas pasal 1 ayat (3) dan pasal 74 ayat (1), (2), (3), dan (4). Legitimasi sangat bermanfaat untuk mendukung keberlangsungan hidup suatu perusahaan.

Hasil penelitian ini selaras dengan penelitian Hadi et al. (2017) bahwa pengaruh corporate social responsibility terhadap financial distress diperkuat dalam tahap mature siklus hidup perusahaan, dan hasil penelitian ini juga mendukung penelitian Hasan dan Habib (2017) yang mengatakan bahwa perusahaan pada tahap mature berinvestasi lebih banyak dalam kegiatan corporate social responsibility dibanding tahap siklus hidup perusahaan yang lain dikarenakan sudah mempunyai keunggulan kompetitif.

\section{Hubungan antara Ukuran Perusahaan (SIZE) dan Financial Distress}

Berdasarkan hasil penelitian ini, variabel size tidak berpengaruh signifikan terhadap financial distress. Hal ini menunjukkan bahwa terjadinya financial distress pada suatu perusahaan tidak bergantung pada besar atau kecilnya ukuran (SIZE) suatu perusahaan. Hasil penelitian ini selaras dengan penelitian Ayu (2017).

\section{Hubungan antara Leverage (LEV) dan Financial Distress}

Berdasarkan hasil penelitian ini, variabel LEV (leverage) berpengaruh positif dan signifikan terhadap financial distress. Hal ini menunjukkan semakin besar leverage yang dimiliki perusahaan ,maka semakin besar indikasi terjadinya financial distress, begitupun sebaliknya. Hasil penelitian ini selaras dengan penelitian Lee (2010) dan Hadi et al. (2017).

\section{Hubungan antara Cash Holding (CH) dan Financial Distress}

Berdasarkan hasil penelitian ini, variabel $\mathrm{CH}$ (Cash Holding) tidak berpengaruh signifikan terhadap financial distress. Hal ini dapat dikatakan bahwa terjadinya financial distress pada suatu perusahaan tidak bergantung dari jumlah kas dan short investment yang dimiliki perusahaan. Hasil penelitian ini tidak mendukung penelitian Hadi et al. (2017) yang menemukan bahwa cash holding memiliki pengaruh yang signifikan terhadap financial distress.

\section{PENUTUP}

Penelitian ini ditujukan untuk membuktikan secara empiris mengenai pengaruh corporate social responsbility, dan interaksi antara corporate social responsbility dan siklus hidup perusahaan pada tahap mature terhadap financial distress. Penelitian ini menggunakan sampel perusahaan manufaktur yang listed di Bursa Efek Indonesia periode pengamatan 20142017. Berdasarkan hasil penelitian diperoleh kesimpulan yaitu corporate social responsibility berpengaruh negatif dan signifikan terhadap financial distress, dan siklus hidup perusahaan pada tahap mature memperkuat pengaruh corporate social responsbility terhadap financial distress. Implikasi penelitian ini ialah memberikan saran pada perusahaan manufaktur dapat meningkatkan pelaksanaan CSR serta bisa memberikan informasi mengenai teori yang digunakan dan bisa menjadi referensi pada penelitian selanjutnya.Keterbatasan penelitian ini dikarenakan lingkup waktu penelitian yang terlalu pendek dan batasan industri yang sempit, serta belum adanya alat ukur yang tepat untuk mengukur besaran pengungkapan Corporate 
Social Responsibility di Indonesia. Sarannya adalah meneliti sampel perusahaan bukan hanya pada industri manufaktur saja, akan lebih baik jika meneliti seluruh perusahaan publik yang listed di BEI, kemudian menambah periode pengamatan penelitian, dan menggunakan alat ukur yang lebih baik dalam pengukuran tanggung jawab sosial, serta mempertimbangkan variabel lainnya yang belum diuji pada penelitian ini, seperti variabel keuangan.

\section{DAFTAR PUSTAKA}

Achda, B. Tamam. 6 Juni (2008). Konteks Sosiologis Perkembangan Corporate Social Responsibility (CSR) dan Implementasinya di Indonesia. http://www.menlh.go.id/serbaserbi/csr/sosiologi.pdf

Baron, D.P. (2007). Corporate social resposibility and social entrepreneurship. Journal of Economics \& Management Strategy, 16 (3) :683-717.

Brown, N. and Deegan, C. (1998). The public disclosure of environmental performance information-a dual test of media agenda setting theory and legitimacy theory. Accounting and Business Research, 29 (1) :21-41.

Butar, Linda Kurniasih Butar dan Sri Sudarsi. (2012). Pengaruh Ukuran Perusahaan, Profitabilitas, Leverage, dan Kepemilikan Institusional Terhadap Perataan Laba: Studi Empiris Pada Perusahaan Food And Beverage yang Terdaftar Di BEI. Dinamika Akuntansi, Keuangan, dan Perbankan. ISSN:1979-4878, hal. 143-158.

Cho, S. Y., C. Lee, and R. J. Jr Pfeiffer. (2013). Corporate social responsibility performance and information asymmetry. Journal of Accounting \& Public Policy, 32 :71-83.

Darsono \& Ashari. (2005). Pedoman Praktis Memahami Laporan Keuangan. Yogyakarta: Andi

Fahmi Irham. (2013). Analisis Laporan Keuangan. Bandung:Afabeta.

Gill, Amajit, dan Shah, Charul. (2012). Determinant of Corporate Cash Holdings: Evidence from Canada. International Journal of Economics and Finance, 4 (1).

Goss, Allen. (2009). Corporate social responsibility and financial distress.Available at:http://ojs.acadiau.ca/index.php/ASAC/article/viewFile/677/586

Gray, R.H., Owen, D., dan Adam. C. (1996). Accounting and Accountability. Hemel Hempstead: Prentics Hall.

Hadi, Ahmed Al, Bikram Chatterjee, Ali Yaftian,Grantley Taylor, and Mostafa Monzur Hasan. (2017). Corporate social responsbility performance,financial distress, firm life cycle. Journal of Accounting and Finance, hal 1-29, ISSN 0810-5391, DOI:10.1111/acfi.12277.

Hasan, M. M. dan Habib, A. (2017). Corporate Life Cycle, Organizational Financial Resources and Corporate Social Responsibility. Journal of Contemporary Accounting \& Economics, $13: 20-36$.

Juniarti dan Limanjaya, R. (2005). Mana yang Lebih Memiliki Value Relevant: Net Income atau Cash Flows (Studi terhadap Siklus Hidup Organisasi). Jurnal Akuntansi dan Keuangan, 7 (1) :22-42

Kiroyan, Noke. (2006). Good Corporate Governance (GCG) dan Corporate Social Responsibility (CSR) Adakah Kaitan di Antara Keduanya?. Economics Business Accounting Review, Edisi III, hal. 45-58.

Kurnianto, Eko Adhy. (2011). Pengaruh Corporate Social Responsibility Terhadap Kinerja Keuangan Perusahaan (Studi Empiris pada Perusahaan Perbankan yang Terdaftar di Bursa Efek Indonesia Tahun 2005 - 2008). Skripsi. Universitas Diponegoro. 
Lee, Saoki et al. (2010). Moderating effect of capital intensity on the relationship between leverage and financial distress in the U.S. restaurant industry. International Journal of Hospitality Management, $30: 429-438$

Noviana. (2010). Triple bottom line: Lebih dari sekadar profit. Http://swa.co.id/myarticle/triple-bottomline-lebih-dari-sekadar-profit. Diakses pada tanggal 5 Oktober 2015

Subiantoro, O. H. Dan Mildawati T. (2015). Pengaruh Karakteristik Perusahaan terhadap Pengungkapan Corporate Social Responsibility. Jurnal Ilmu dan Riset Akuntansi,4 (9) : $1-21$

Utami, Sri, dan Prastiti, S. D. (2011). Pengaruh Karakteristik Perusahaan Terhadap Social Disclosure. Jurnal Ekonomi Bisnis, 16 (1) :63-69.

Vidiastuty, Deshinta. 2012. Pengaruh Siklus Hidup Perusahaan terhadap Aktivitas Akuisisi. Tesis Universitas Indonesia

Wolk, et al. (2001). Signaling, Agency Theory, Accounting Policy Choice. Accounting and Business Research, 18 (69) :47-56.

www.idx.co.id

www.sahamok.com 